\title{
Нерезонансное обращение волнового фронта света на поверхности пленок GaN при большой мощности оптического возбуждения
}

\author{
(C) А.Н. Грузинцев, А.Н. Редькин \\ Институт проблем технологии микроэлектроники Российской академии наук, \\ 142432 Черноголовка, Московская область, Россия \\ E-mail: gran@iptm.ru
}

(Получена 29 марта 2018 г. Принята к печати 4 апреля 2018 г.)

Теоретически и экспериментально показана возможность нерезонансного обращения волнового фронта света в возбужденной полупроводниковой среде. На эпитаксиальных пленках $\mathrm{GaN}$ при комнатной температуре при накачке азотным лазером впервые обнаружено индуцированное обращение волнового фронта света в видимой и инфракрасной областях спектра. Исследованы зависимости интенсивности сигнала обращения волнового фронта света от энергии фотона и интенсивности лазерной накачки. Предлагается объяснение эффекта: поглощение и преломление света на индуцированных лазером свободных носителях в полупроводниковой среде.

DOI: 10.21883/FTP.2019.01.46982.8877

\section{1. Введение}

Современное состояние оптоэлектроники требует поиска материалов с преобладающим излучением в синем и ультрафиолетовом (УФ) спектральных диапазонах [1]. В настоящее время наиболее перспективными для создания светоизлучающих структур в данной области спектра считаются оксид цинка и нитрид галлия (а также твердые растворы на его основе). Особенно важно получение данных полупроводниковых материалов и структур на их основе с монохроматическим свечением в экситонной или краевой области спектра. Для этого необходимо получение тонких пленок или кристаллов $\mathrm{ZnO}$ и $\mathrm{GaN}$ широкозонных полупроводников высокого кристаллического совершенства, поскольку собственные дефекты кристаллической решетки и неконтролируемые примесные доноры или акцепторы могут вызвать длинноволновый сдвиг люминесценции и появление широких неоднородно уширенных полос свечения в так называемой примесной области спектра [2,3].

Нитрид галлия и оксид цинка - прямозонные материалы, гексагональная модификация которых имеет при комнатной температуре ширину запрещенной зоны 3.428 и 3.37 эВ соответственно. Ультрафиолетовое свечение может быть обусловлено рекомбинацией свободных экситонов гексагональной фазы. Согласно литературным данным [4,5], энергия связи электрона и дырки в экситоне $\mathrm{ZnO}$ составляет 60 мэB, а в $\mathrm{GaN}-25$ мэВ. Поэтому экситоны в оксиде цинка термически стабильны при комнатной температуре и возможно получение лазерного эффекта при рекомбинации экситонов. Экситонный механизм лазерной генерации довольно эффективен, что позволяет получать низкие пороговые мощности оптической накачки от $24 \mathrm{KBT} / \mathrm{cm}^{2}$ и выше [6]. В нитриде галлия при комнатной температуре экситоны термически нестабильны и вынужденное излучение в краевой области получается, как правило, при рекомбинации электроннодырочной плазмы (ЭДП), что обусловливает резкий рост пороговой мощности накачки до $1.2 \mathrm{MBT} / \mathrm{cm}^{2}$ и использование лазерных резонаторов микронного размеpa [7]. Именно поэтому для увеличения энергии связи экситона и понижения порога генерации при создании полупроводниковых лазеров на основе $\mathrm{GaN}$ применяют структуры с квантовыми ямами.

Тем не менее изучение механизмов излучательной рекомбинации ЭДП в нитриде галлия представляет большой интерес для создания полупроводниковых лазеров большой мощности поскольку при существенном превышении пороговых режимов оптической или электрической накачки экситонный механизм лазерной генерации уступает место механизму рекомбинации электроннодырочной плазмы. Это делает нитрид галлия перспективным для создания мощных полупроводниковых лазерных источников света в УФ спектральном диапазоне с большим порогом накачки. Однако при сильном возбуждении полупроводника начинают происходить различные нелинейные оптические явления. Так, в работе [8] была теоретически и экспериментально показана возможность резонансного обращения светового волнового фронта $(\mathrm{OCВФ)} \mathrm{в} \mathrm{возбужденной} \mathrm{полупроводниковой} \mathrm{среде.} \mathrm{На}$ эпитаксиальных пленках $\mathrm{ZnO}$ при комнатной температуре при накачке азотным лазером авторы обнаружили обращение света для энергии фотонов, равной половине энергии излучательной рекомбинации экситонов. Исследованы зависимости интенсивности сигнала ОВФ от его спектрального состава. Предложено объяснение эффекта: квадратичное взаимодействие световых и экситонных электромагнитных колебаний в полупроводниковой среде.

Интересно исследовать эффект ОВФ при интенсивном оптическом возбуждении в другом широкозонном полупроводнике - GaN. В этом случае при ком- 
натной температуре уже практически не происходит образование свободных экситонов. Основным каналом излучательной рекомбинации является рекомбинация ЭДП. Цель данной работы заключалась в исследовании эффектов обращения волнового фронта и отражения электромагнитных волн на электронно-дырочной плазме в сильно возбужденном ультрафиолетовым лазером нитриде галлия.

\section{2. Эксперимент}

Пленки нитрида галлия были синтезированы модифицированным хлоридно-гидридным методом химических транспортных реакций (CVD) [9]. В отличие от традиционной методики в данном случае в качестве исходных компонентов использовали металлический галлий $(99.999 \%)$ и хлорид аммония (ОСЧ). Высокочистый азот (марки ПНГ) служил газом-носителем. Процесс проводили в двухзонном горизонтальном кварцевом реакторе. В первой зоне осушествлялось взаимодействие галлия, нагретого до температуры $400^{\circ} \mathrm{C}$, с хлоридом аммония. Образующиеся при этом пары моноаммиаката трихлорида галлия током азота переносились во вторую зону, где разлагались с образованием нитрида галлия. Температура пиролиза составляла $950^{\circ} \mathrm{C}$. В качестве подложки использовали сапфир (0001). Полученные пленки нитрида галлия, согласно данным электронной микроскопии [9], имели поликристаллическую структуру со средними размерами отдельных кристаллитов около 0.4 мкм. Они обладали электронным типом проводимости с довольно низким удельным сопротивлением 10 Ом·см. Правильная гексагональная форма поликристаллов говорила о преобладании гексагональной модификации $\mathrm{GaN}$, что было подтверждено методом рентгеновской дифрактометрии.

Спектры фотолюминесценции (ФЛ) регистрировались при возбуждении азотным лазером с длиной волны 337.1 нм (LGI-505, с длительностью импульса 0.6 нс и энергией в импульсе 1.4 мДж) или перестраиваемым по длине волны излучением ксеноновой лампы, прошедшим через монохроматор. В обоих случаях возбуждение носило межзонный характер, но если ксеноновая лампа давала малую плотность мощности на образце $50 \mathrm{~B} / \mathrm{cm}^{2}$, то использование азотного лазера с набором поглотителей позволяло получать плотность мощности от $50 \mathrm{KBT} / \mathrm{cm}^{2}$ до $70 \mathrm{MBT} / \mathrm{cm}^{2}$.

Схема установки использованной для измерения сигнала обращения волнового фронта и фотолюминесценции на пленках нитрида галлия показана на рис. 1. Здесь важно отметить, что падающая на образец световая волна была от лампы накаливания „Нарва-100“, запитанной источником постоянного тока, и падала на образец под углом к его поверхности, чтобы геометрически отраженный свет не попадал в регистрирующий монохроматор МДР-6. Свет лампы накаливания после прохождения через светосильный монохроматор МДР-12 был непрерыв-

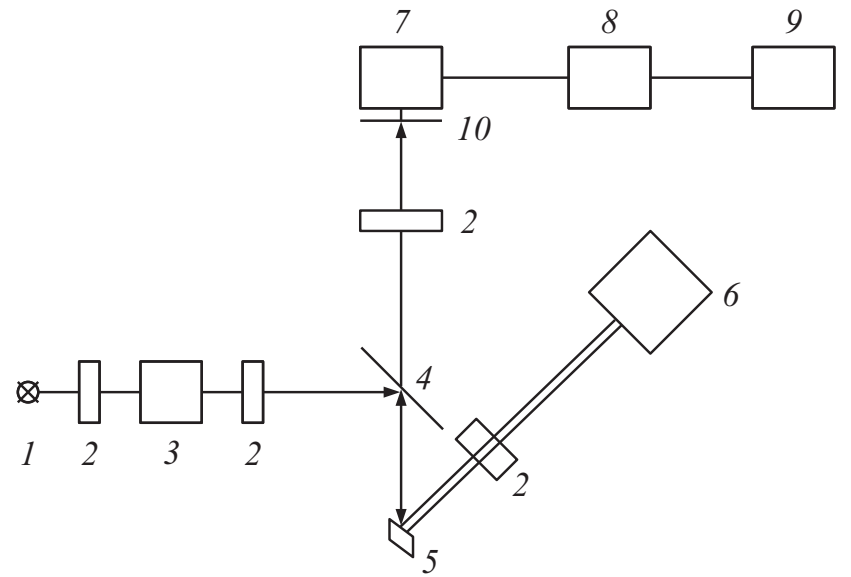

Рис. 1. Схема установки, использованной для измерения отражения и обращения волнового фронта света на пленке нитрида галлия: 1 - источник света „Нарва-100“, 2 - линзы, 3 - монохроматор МДР-12, 4 - расщепитель пучка, 5 образец $\mathrm{GaN}, 6$ - азотный лазер, 7 - монохроматор МДР-6, 8 - фотоумножитель ФЭУ-79 или ФЭУ-62, 9 - система регистрации спектра и $10-$ светофильтр.

ным во времени и имел спектральную полуширину не хуже 4 нм. Система регистрации спектра была настроена на частоту возбуждающего азотного лазера и состояла из усилителя переменных сигналов „Unipan-237“ с выходом на компьютер. Лазерный пучок фокусировался на поверхности пленки в пятно диаметром менее 100 мкм, что позволяло получать плотность мощности накачки порядка $108 \mathrm{BT} / \mathrm{cm}^{2}$. Совмещение светового и лазерного пятен на образце контролировалось с помощью оптического микроскопа. В качестве расщепителя света (рис. 1) использовалась обычная стеклянная пластина. При регистрации спектров отраженного сигнала и люминесценции пленки использовались светофильтры КС-15 и С 3 -23 соответственно для удаления паразитных сигналов 2-го порядка двойного монохроматора МДР-6 в регистрируемых спектрах.

\section{1. Теория}

Рассмотрим распространение света в полупроводниковой среде, диэлектрическая $\varepsilon$ (или магнитная $\mu$ ) проницаемость которой в какой-то момент времени $t_{0}=0$ плавно или ступенчато (рис. 2) изменяется от величины $\varepsilon_{1}$ до величины $\varepsilon_{2}$. Вообще говоря, два фундаментальных явления могут изменять оптические свойства полупроводника под действием мощного импульса лазера с энергией кванта больше ширины запрещенной зоны и при концентрации возбуждаемых электронно-дырочных пар (ЭДП), близкой к порогу Мотта. Во-первых, это перенормировка электронного спектра вследствие экранирования кулоновского взаимодействия. Вторым важным фактором является возникновение плазменных колебаний и их взаимодействие с оптическими фоно- 


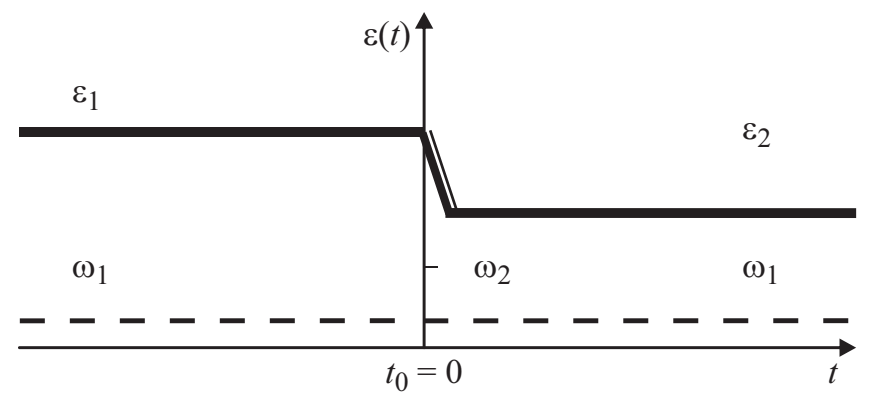

Pис. 2. Изменение во времени диэлектрической проницаемости среды и эффективной частоты света в ней под действием УФ лазерного импульса в момент времени $t_{0}=0$.

нами, которое приводит к перенормировке фононного спектра - образованию смешанных фонон -плазмонных мод. Изменение оптических постоянных различных полупроводников под действием мощных лазерных импульсов наблюдалось методами фотолюминесценции и комбинационного рассеяния света. При этом характерные времена изменений (рис. 2) находились в пикосекундном диапазоне.

Уравнения Максвелла световой волны в полупроводниковой среде (рис. 2) принимают вид волнового уравнения [10]:

$$
\Delta E-\varepsilon \mu / c^{2} \cdot d^{2} E / d^{2} t=0
$$

где $E(x, t)$ - волновой вектор электрического поля световой волны, а $\varepsilon(t), \mu$ - диэлектрическая и магнитная проницаемость среды, $c$ - скорость света. Для простоты будем искать решение волнового уравнения в виде однородных волн, движущихся вдоль оси $X: E=E_{0} \exp (i \omega t-i k x n)$. При этом будем рассматривать изменение во времени амплитуды и частоты электромагнитной волны в какой-либо фиксированной точке пространства $X=x_{0}$. Разложим в ряд Тейлора изменение по времени показателя преломления среды $n(t)=(\varepsilon \mu)^{1 / 2}=n_{1}+d n / d t \cdot t+\ldots$ и решение волнового уравнения с учетом комплексно сопряженной (К.С.) части примет вид

$$
E=E_{0} \exp \left(i \omega t-i k x_{0} \cdot d n / d t \cdot t-i k x_{0} \cdot n_{1}\right)+\text { K.C. }
$$

Тогда волновое уравнение (1) для временно́й составляющей $E(\omega, t)$ световой волны после дифференцирования в Лапласиане примет вид

$$
d^{2} E / d^{2} t+k^{2} c^{2} /(\varepsilon \mu) \cdot E=0
$$

Здесь от времени зависит также диэлектрическая проницаемость, изменяющаяся по ступенчатому закону в момент времени $t_{0}=0$ перехода Мотта в полупроводниковой среде (рис. 2). Пусть до перехода (при $t<0)$ диэлектрическая проницаемость была $\varepsilon_{1}$ и тогда решение уравнения (2) имеет вид: $E_{1}=A \exp \left(i \omega_{1} t\right)+B \exp \left(-i \omega_{1} t\right)$, где $\omega_{1}=\omega=k c / n_{1}$. После изменения диэлектрической проницаемости среды (при $t>0$ ) решение уравнения (2) следует искать в виде волн другой частоты: $E_{2}=\exp \left(i \omega_{2} t\right)$, где $\omega_{2}=\omega-k x_{0} \cdot d n / d t$. Постоянные $A$ и $B$ определяются из условия непрерывности во времени световой волны и ее производной при $t_{0}=0$ (рис. 2). Что дает соотношения

$$
1=A+B, \quad \omega_{2}=\omega_{1} A-\omega_{1} B .
$$

Откуда имеем выражения для амплитуд прошедшей и отраженной волны:

$$
A=\left(\omega_{1}+\omega_{2}\right) / 2 \omega_{1} \quad \text { и } \quad B=\left(\omega_{1}-\omega_{2}\right) / 2 \omega_{1} .
$$

Таким образом, в момент переключения диэлектрической проницаемости среды световая волна в среде с учетом пространственной части имеет вид

$$
E_{1}=A \exp \left(i \omega_{1} t-i k x\right)+B \exp \left(-i \omega_{1} t-i k x\right),
$$

где $\omega_{1}=k c / n_{1}$, а постоянные $A$ и $B$ определяются выражением (4). При этом видно, что если первое слагаемое представляет волну, двигающуюся в положительном направлении оси $X$, то второе дает обращенную волну, движущуюся навстречу первой. Происходит обращение волнового фронта света в среде с изменяющимися в момент падения возбуждающего лазерного импульса оптическими характеристиками. Амплитуда обращенной световой волны, согласно (4), пропорциональна производной изменения показателя преломления и толщине слоя, в котором происходит изменение $B=k x_{0} /(2 \omega) \cdot d n / d t$. Если временны́х изменений оптических параметров $-\varepsilon(t)$ среды нет (при малой интенсивности импульсного лазера или при непрерывном лазерном возбуждении), то ОВФ не происходит.

\section{3. Результаты и их обсуждение}

В работе [11] исследовалось влияние температуры и плотности оптического возбуждения на спектральные характеристики и интенсивность свечения ЭДП и свободных экситонов в пленках $\mathrm{GaN}$. Из всего набора образцов нитрида галлия [11] мы выбрали пленки, у которых даже при малой интенсивности возбуждения ксеноновой лампой в спектре ФЛ преобладала полоса рекомбинации ЭДП, а линия свечения свободных экситонов при комнатной температуре была на порядок меньше. При более мощном возбуждении азотным лазером в спектрах ФЛ присутствовала лишь полоса ЭДП. На рис. 3 показаны кривые свечения образцов при различных мощностях оптической накачки от $50 \mathrm{KBT} / \mathrm{cm}^{2}$ (кривая 1) до $50 \mathrm{MBт} / \mathrm{cm}^{2}$ (кривая 6). Видно, что при столь больших плотностях мощности возбуждения в ФЛ пленок $\mathrm{GaN}$ превалирует полоса ЭДП, максимум которой незначительно сдвигается в длинноволновую сторону от 3.2 до 3.19 эВ с увеличением мощности накачки на 3 порядка величины. Характер зависимости 


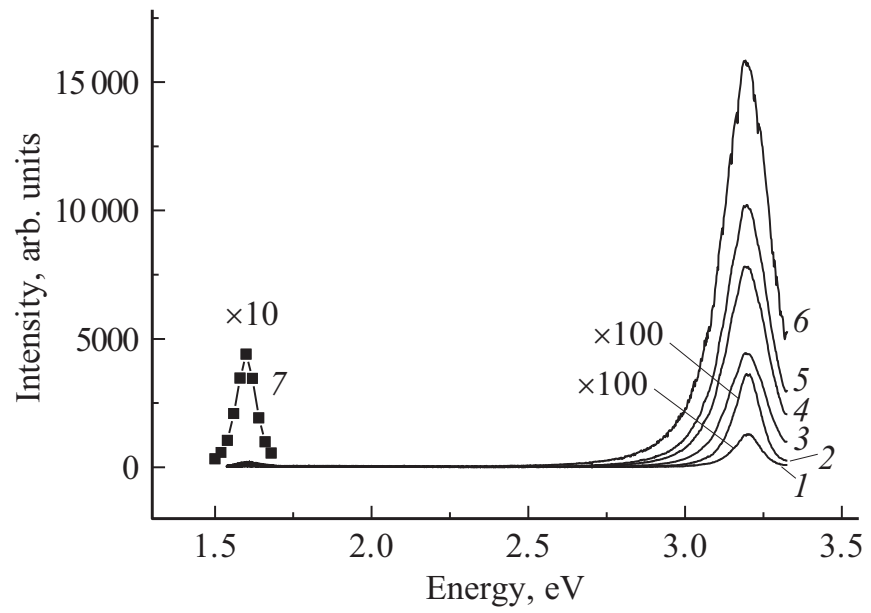

Pис. 3. Спектры фотолюминесценции пленки $\mathrm{GaN}$ при различных интенсивностях возбуждающего азотного лазеpa: $50 \mathrm{KBT} / \mathrm{cm}^{2} \quad(1), \quad 122 \mathrm{KBT} / \mathrm{cm}^{2} \quad(2), \quad 5.87 \mathrm{MBT} / \mathrm{cm}^{2} \quad(3)$, $15.5 \mathrm{MBT} / \mathrm{cm}^{2}$ (4), $23.4 \mathrm{MBT} / \mathrm{cm}^{2}$ (5) и $50 \mathrm{MBT} / \mathrm{cm}^{2}$ (6), а также интенсивности сигнала резонансного обращения волнового фронта (7) при плотности возбуждения $50 \mathrm{MBT} / \mathrm{cm}^{2}$. $T=300 \mathrm{~K}$.

площади под кривой свечения и ширины линии люминесценции на полувысоте от интенсивности лазерного возбуждения свидетельствует о ее спонтанном характере во всем диапазоне измерений. Дело в том, что площадь под кривой ФЛ росла почти линейно, а ширина линии плавно возрастала от 0.106 до 0.176 эВ. В случае стимулированной люминесценции рост площади был бы сверхлинейным с явно выраженным пороговым значением, а ширина линии, наоборот, уменьшалась бы для надпороговых плотностей мощности.

Теперь одновременно с импульсным возбуждением азотным лазером (плотность мощности $50 \mathrm{MBT} / \mathrm{cm}^{2}$ ) направим на образец непрерывный по времени световой поток из красной спектральной области с энергией фотона от 1.5 до 1.7 эВ, равной половине энергии излучательной рекомбинации ЭДП в нитриде галлия. В момент лазерного импульса возникает обращение волнового фронта непрерывной подсветки на плазменных колебаниях пленки. На рис. 3 (кривая 7) построена зависимость интенсивности обращенной волны в максимуме от его спектрального положения. Видно, что сигнал ОВФ имеет максимальную интенсивность при энергии падающих фотонов 1.60 эВ, совпадающей с половиной энергии пика рекомбинации ЭДП. В работе [8] резонансное ОВФ происходило на экситонах в оксиде цинка. В нашем случае происходит резонансное ОВФ на электромагнитных колебаниях ЭДП, также обладающих нулевым волновым вектором. Отметим, что, согласно приведенным в [8] теоретическим выкладкам, для сред с квадратичной оптической нелинейностью может возникать резонансное обращение волнового фронта при энергии фотонов падающего света, равной половине энергии электромагнитных колебаний поляритонов в среде с нулевым волновым вектором (экситоны, плазмоны, фононы или примесные состояния). При этом интенсивность резонансной обращенной волны пропорциональна интенсивности падающего света и интенсивности стоячей волны электромагнитных колебаний ЭДП.

Интересно отметить, что для случая нитрида галлия, в процессе образования ЭДП, имеется также сигнал ОВФ света в нерезонансных красной и инфракрасной (ИК) областях спектра (рис. 4 и 5). При этом интенсивность сигнала нерезонансного обращения волнового фронта на порядок меньше интенсивности резонансного ОВФ (рис. 3, кривая 7) и увеличивается с увеличением длины волны падающего непрерывного света в ИК спектральную область (рис. 5, кривые 1-4). Остановимся подробнее на зависимости сигнала нерезонансного ОВФ от мощности накачки импульсного азотного лазера (рис. 6).

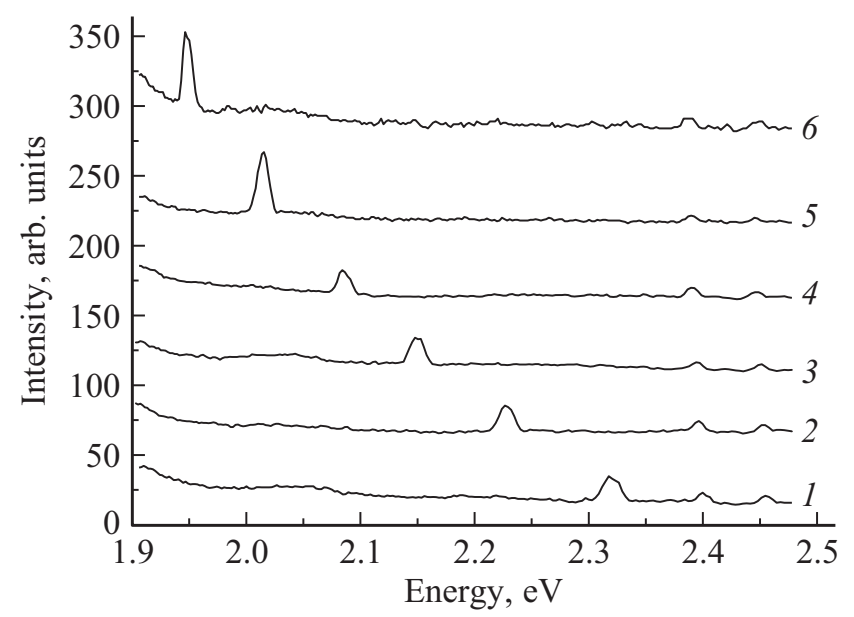

Рис. 4. Спектр сигнала нерезонасного ОВФ пленки GaN в красной спектральной области при энергии фотонов падающего света, эВ: $1-2.32,2-2.225,3-2.15,4-2.07,5-2.01$ и $6-1.95$. Температура измерений $T=300 \mathrm{~K}$.

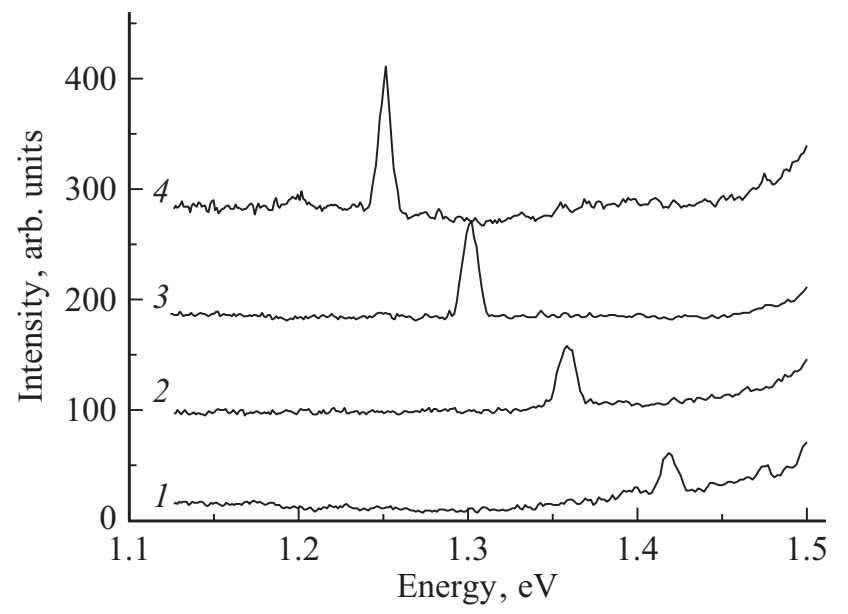

Рис. 5. Спектр сигнала нерезонансного ОВФ пленки GaN в инфракрасной спектральной области при энергии фотонов падающего света, эВ: $1-1.42,2-1.355,3-1.30$ и $4-1.24$. Температура измерений $T=300 \mathrm{~K}$. 


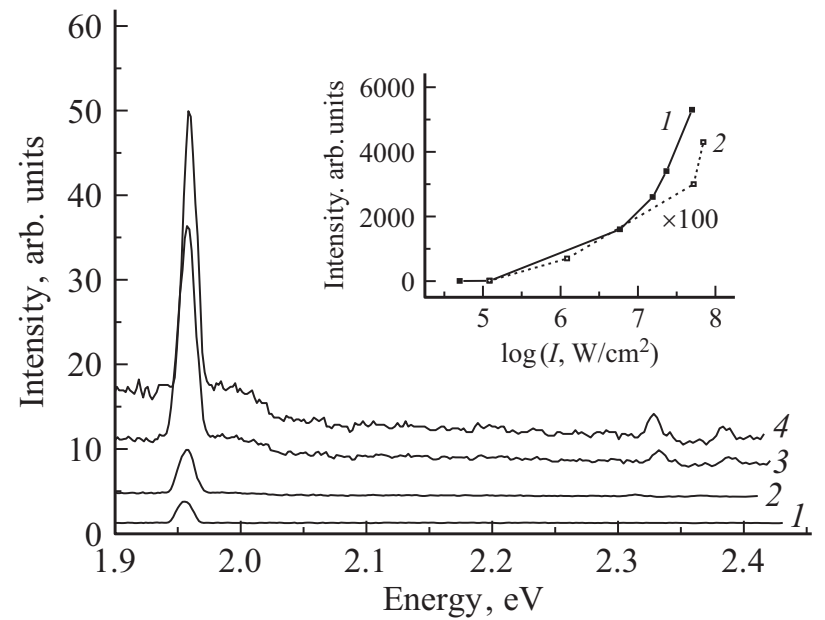

Pис. 6. Спектры сигнала модулированного ОВФ пленки $\mathrm{GaN}$ при различных интенсивностях возбуждающего азотного лазера, МВт/см ${ }^{2}: 1-0.70,2-1.22,3-52.5$ и $4-70$ и энергии фотонов падающего света гелий-неонового лазера 1.958 эВ. На вставке - зависимость интенсивностей сигналов ФЛ ЭДП с максимумом 3.2 эВ (1) и модулированного ОВФ с максимумом 1.958 эВ (2) пленки $\mathrm{GaN}$ от интенсивности возбуждающего азотного лазера. $T=300 \mathrm{~K}$.

Использование калиброванных поглотителей света позволило нам получить набор мощностей: $0.70 \mathrm{MBT} / \mathrm{cm}^{2}$ (кривая 1), $1.22 \mathrm{MBT} / \mathrm{cm}^{2}$ (кривая 2), $52.5 \mathrm{MBT} / \mathrm{cm}^{2}$ (кривая 3) и $70 \mathrm{MBT} / \mathrm{cm}^{2}$ (кривая 4 ) ультрафиолетового возбуждения пленок $\mathrm{GaN}$. Видно, что интенсивность сигнала обращения волнового фронта света гелий-неонового лазера с энергией фотона 1.958 эВ растет нелинейно с интенсивностью УФ-накачки без изменения положения максимума.

Прежде чем рассматривать физический механизм нерезонансного ОВФ в исследованных пленках нитрида галлия, вспомним, что часто монокристаллы широкозонных полупроводников (карбид кремния, оксид цинка или нитрид галлия) с сильной электронной проводимостью имеют зеленый цвет. Это происходит благодаря поглощению падающего света красного и ИК диапазонов на свободных носителях материала [12]. Причем коэффициент поглощения возрастает с увеличением длины волны света. Что же будет происходить с падающим на пленку нитрида галлия видимым и ИК светом, если мы в момент времени $t=0$ с помощью импульса мощного ультрафиолетового лазера будем создавать в ней множество свободных носителей (электронов и дырок). Очевидно, что среда в этот момент времени из прозрачной будет становиться более поглощающей. Согласно [13], коэффициент поглощения света на свободных носителях в полупроводниках равен

$$
\alpha=4 \cdot \pi \cdot e^{2} \cdot N /\left(c \cdot m \cdot \tau \cdot \omega^{2}\right),
$$

где $N$ - концентрация свободных носителей, $m$ и $e-$ их эффективная масса и заряд, $\tau-$ усредненное время жизни носителей, в течение которого полностью теряется скорость направленного движения, $\omega$ и $c$ - частота и скорость падающего света. Таким образом, поглощение непрерывного света индуцированными лазерным импульсом свободными носителями в пленке нитрида галлия должно быть пропорционально их концентрации и обратно пропорционально квадрату частоты падающего света. Поскольку показатель преломления для света, падающего на образец, связан с коэффициентом поглощения, то значение коэффициентов преломления $n$ и поглощения $\alpha$, согласно [13], измененяется в момент лазерного импульса на поверхности образца в тонком слое порядка 100 нм. Следовательно, если в момент лазерного импульса индуцированные свободные носители в нитриде галлия сильно поглощают в некоторой области спектра, то они и сильнее преломляют свет в той же области.

Именно за счет изменения концентрации свободных носителей в пленках $\mathrm{GaN}$ при возбуждении УФ лазерным импульсом происходит изменение показателя преломления и появление сигнала ОВФ в красной или инфракрасной области спектра (рис. 4 и 5). Происходит модуляция непрерывного света от лампы накаливания, прошедшего через монохроматор, с частотой азотного лазера. Этот модулированный или индуцированный мощным лазером сигнал ОВФ мы и регистрировали в геометрии обратного отражения от поверхности пленок нитрида галлия. Причем в этом полупроводнике возбужденные носители существуют как раз в свободном виде при комнатной температуре измерений из-за малой энергии связи экситона. Анализ выражений (3) и (4) показывает увеличение амплитуды модуляции коэффициента отражения с увеличением интенсивности УФ возбуждения (увеличение концентрации свободных носителей) и с увеличением длины волны падающего света. Это хорошо согласуется с данными измерений сигнала модулированного ОВФ для разных мощностей оптической УФ накачки (рис. 6) и для разных длин волн падающего света (рис. 4 и 5). Виден также рост интенсивности сигнала модулированного отражения в ИК области спектра по сравнению с видимой областью спектра .

Отметим также, что сравнение эффективности нерезонансного обращения волнового фронта, индуцированного ультрафиолетовым лазером, в пленках нитрида галлия и оксида цинка [8] при одном и том же уровне мощного оптического возбуждения явно не в пользу последнего. В оксиде цинка из-за большой энергии связи возбужденных носителей в свободный экситон при комнатной температуре в спектрах ФЛ превалирует экситонное свечение, а не излучение ЭДП. Поэтому практически все возбужденные лазером носители присутствуют в пленках оксида цинка не в свободном виде, а в виде свободных экситонов. Однако последние электрически нейтральны и не дают вклад в проводимость материала и в поглощение света за счет проводимости среды, которую мы и модулируем азотным лазером в данном эксперименте. 


\section{4. Заключение}

Таким образом, обнаруженное нами индуцированное (или модулированное) обращение волнового фронта света (ОВФС) от поверхности пленок $\mathrm{GaN}$ при больших мощностях ультрафиолетовой импульсной накачки можно объяснить процессами генерации свободных носителей или электронно-дырочной плазмы. При этом с ростом мощности накачки также происходит значительное уширение линии люминесценции ЭДП за счет увеличения кинетической энергии электронов и дырок в плазме. ЭДП-плазма вызывает локальное увеличение проводимости и связанное с этим увеличение поглощения света на свободных носителях. При этом интенсивность ОВФ света также возрастает в месте падения лазерного луча при временном изменении диэлектрической проницаемости среды. Сверхлинейная зависимость (рис. 6) интенсивности индуцированного ОВФ от интенсивности возбуждения нитрида галлия обусловливается ее зависимостями (3) и (4) от концентрации индуцированных свободных носителей во всем диапазоне мощностей накачки от $50 \mathrm{BT} / \mathrm{cm}^{2}$ до $50 \mathrm{MBT} / \mathrm{cm}^{2}$. Для получения сигнала индуцированного ОВФ в нитриде галлия с большей интенсивностью необходимо использование пробного оптического излучения с большей длиной волны из более инфракрасной области спектра. Перспективным является использование метода индуцированного ОВФ для определения концентрации и пространственного распределения возбужденных свободных носителей на поверхности полупроводниковой пленки.

\section{Список литературы}

[1] S. Nakamura, T. Mukai, M. Senoh. Jpn. J. Appl. Phys., 30, L1998 (1991).

[2] S.J. Xu, G. Li, S.J. Chue. Appl. Phys. Lett., 72, 2451 (1998).

[3] E.R. Glaser, T.A. Kennedy, K. Doverspike. Phys. Rev. B, 51, 13326 (1995).

[4] M.H. Huang, S. Mao, H. Feiick, H. Yan, Y. Wu, H. King, E. Waber. Science, 292, 1897 (2001).

[5] J.W. Tomm, B. Ullich, X.G. Qui, Y. Segava, A. Ohtomo, V. Kawasaki. J. Appl. Phys., 87, 1844 (2000).

[6] P. Zu, Z.K. Tang, G.K. Wong, M. Kawasfki, A. Ohtomo, H. Koinuma, Y. Segawa. Sol. St. Commun., 103, 459 (1997).

[7] X.H. Yang, T.J. Schmidt, W. Shan, J.J. Song. Appl. Phys. Lett., 66, 1 (1995).

[8] А.Н. Грузинцев, В.Т. Волков. ФТП, 38 (5), 543 (2004).

[9] А.Н. Редькин, В.И. Таций, З.И. Маковей, А.Н. Грузинцев, Е.Е. Якимов. Неорг. матер., 40 (10), 1197 (2004).

[10] Ф. Качмарек. Введение в физику лазеров (М., Мир, 1981) c. 256.

[11] А.Н. Грузинцев, А.Н. Редькин, К. Бартхоу. ФТП, 39 (10), 1200 (2005).

[12] D.G. Thomas. J. Phys. Chem. Solids, 9, 31 (1958).

[13] П.С. Киреев. Физика полупроводников (М., Высш. шк., 1975) гл. 8, с. 500.

Редактор Г.А.Оганесян

\section{Nonresonant phase conjugation of light on the GaN thin film surface under large density of optical pumping}

\author{
A.N. Gruzintsev, A.N. Redkin \\ Institute of Microelectronics Technology Problems \\ of Russian Academy of Sciences, \\ 142432 Chernogolovka, Russia
}

Abstract The opportunity of the nonresonant phase conjugation of light (NPCL) in the excited semiconductor was shown theoretical and experimental. The induced NPC of light in the visibal and infrared spectral region was detected on the $\mathrm{GaN}$ epitaxial films at room temperature by nitrogen laser pumping. The dependences of the NPCL signal intensity on its photon energy and on the intensity of laser pumping were investigated. This effect explanation was given: absorption and refraction of the light on the laser induced free carriers in the semiconductor. 